\title{
Calendrical Calculation
}

Published in Infancia y Aprendizaje, 2001, 93, 53-65

Running head: CALENDRICAL CALCULATION

Why and how people of limited intelligence become calendrical calculators

Richard Cowan, Neil O’Connor and Katerina Samella

Institute of Education University of London

KEYWORDS: savant syndrome, autism, memory, intelligence, exceptional individuals

\section{Author Notes}

Neil O’Connor, Psychology and Special Needs; Richard Cowan, Katerina Samella, Child Development and Learning.

Tragically, Neil O'Connor died while the research was conducted. We miss his intellectual leadership and unfailing good humour.

The sample of calendrical savants came from the pool built up over several years by Dr O’ Connor and Dr Beate Hermelin. We thank Dr Hermelin and Dr Lisa Heavey for introducing us to two more. We thank an anonymous benefactor, the University of London Central Research Fund, and the University of London Tregaskis Bequest for financial support. We thank the savants, their families and carers for their co-operation.

Correspondence and requests for reprints should be addressed to Dr Richard Cowan, Child Development and Learning, Institute of Education University of London, 20 Bedford Way, London WC1H 0AL, UK. Electronic mail may be sent via Internet to r.cowan@ioe.ac.uk. 


\begin{abstract}
Calendrical calculation is the rare talent of naming the days of the week for dates in the past and future. Calendrical savants are people with low measured intelligence who have this talent. This paper reviews evidence and speculation about why people become calendrical savants and how they answer date questions. Most savants are known to have intensively studied the calendar and show superior memory for calendrical information. As a result they may answer date questions either from recalling calendars or by using strategies that exploit calendrical regularities. While people of average or superior intelligence may become calendrical calculators through internalising formulae, the arithmetical demands of the formulae make them unlikely as bases for the talents of calendrical savants. We attempt to identify the methods used by a sample of 10 savants. None rely on an internalised formula. Some use strategies based on calendrical regularities probably in conjunction with memory for a range of years. For the rest a decision between use of regularities and recall of calendars cannot be made.
\end{abstract}


Why and how people of limited intelligence become calendrical calculators

Calendrical calculators are people who can tell you the days of the week for dates in the past, and sometimes the future. Some of them can also nominate years with particular calendrical features, such as having five Wednesdays in July. They perform these feats without using external aids such as reference books or calendars and do not need to write down intermediate steps. While these are remarkable achievements in themselves, what has particularly intrigued psychologists is the discovery of such talents in people with restricted intellectual ability. Calendrical calculation has been placed alongside exceptional talents in drawing, music, memory, and language learning as an example of savant syndrome (Nettelbeck, 1999; Treffert, 1989). Several case studies of calendrical savants have appeared since Langdon Down's original description of a 38 year old man with a phenomenal memory for numbers who could answer questions for dates in a period of five years (Tredgold \& Soddy, 1956). Most calendrical savants would appear to have developed their talents while children without instruction by others. In this paper we shall review the explanations of why people acquire this talent and how they answer date questions. We shall then use characteristics of our sample of savants to attempt to identify their methods.

Why do people become calendrical calculators?

Why anybody should want to learn to calculate dates is at first sight puzzling. Such a skill has no obvious purpose or value. In contrast to art or music, where exceptional skill is highly regarded in Western culture, prodigious skill in date calculation holds limited appeal. One of us knew a university professor who could calculate dates but was rather ashamed of his talent and we have been told of another high-functioning autistic calculator who gave up doing it because he thought it was childish. A party trick it may be, yet it is one that succeeds in 
impressing other people and providing the calculator with plenty of social reinforcement:

Gould (1997) describes the attention and approval his son receives through being able to tell people what day of the week they were born on. While praise and approval may encourage calculators to develop their talent further, it still does not explain why they would begin to develop it. Calendrical calculation is an uncommon skill, so children who become calculators are unlikely to have met anyone who could do it, or seen that such a skill attracts attention. Intriguingly, one of the more adept calculators in our sample assumes that other people share his skill in date calculation and memory for birthdays.

If the initial motivation to become a calendrical calculator is not social, then it might be intrinsic to the object of study or the person. In speculating what might lead someone to become a calendrical calculator, one may consider what may attract them to study the calendar. Although the calendar is a fascinating product of human science and religion, no previous report describes a calendrical calculator as being interested in the history of the calendar. Indeed questioning our sample of 10 calculators revealed only one who knew about the origins of the calendar. Nor do they show interest in astronomy. This would be relevant as astronomers sometimes use Julian day numbers (the number of days since noon at Greenwich on January $1^{\text {st }} 4713$ B.C.) for observations and finding the day of the week from a given Julian date is straightforward (Duffett-Smith, 1981).

Neither of the above seem to explain why calendars fascinate children who become calendrical calculators. Perhaps calendars attract these children because of the social significance of birthdays, holidays and religious festivals. Perusal of calendars could lead them to discover the variable relation between dates and days of the week in different years, and the calendrical patterns between months in the same year and across years. Learning these patterns might lead either to a method of date calculation, as detailed in the next section, or efficient 
memorising of calendars.

According to this account, anyone may become a calendrical calculator from studying the calendar. Apart from a congenitally blind girl (Rubin \& Monaghan, 1965), calendrical calculators are known to have studied calendars and some are reported to have access to perpetual calendars (Horwitz, Kestenbaum, Person, \& Jarvik, 1965; Young \& Nettelbeck, 1994). However, many children are interested in knowing when their birthdays and Christmas will be, but few become calendrical calculators. This has led to speculation about whether calendrical calculators have some unusual personal characteristics that explain why they, but not others, develop the talent. Calendrical calculation is, like other savant skills, more common in the autistic population than in the general population of people with intellectual disabilities: about 1 in 10 autistic people have a savant skill (Rimland, 1978) while the estimate for people with intellectual disabilities is 1 in 2000 (Hill, 1977). Possibly, some features characteristic of autism may facilitate development of savant skills. Both routines and obsessive preoccupations have long been considered cardinal symptoms of autism (Frith, 1989) and both may contribute to developing calendrical calculation skill. If someone has particular routines for different days of the week, this makes day-date correspondences particularly salient. If they are obsessively preoccupied with the calendar, they will spend a much longer time studying it than others. Consistent with this, both autistic and nonautistic savants showed more obsessional and repetitive behaviour than controls matched for IQ and diagnosis (O'Connor \& Hermelin, 1991).

Another hypothesis linking savant skills and autism is that the development of savant skills may be aided by weak central coherence, a cognitive processing style characteristic of autistic people (Frith, 1989). Weak central coherence refers to a piecemeal processing style that focuses on local features at the expense of global features, perceptual forms or meaning. 
Weak central coherence is proposed to explain the characteristically uneven profiles of autistic people on Wechsler Intelligence Scales, with a peak on the Block Design subscale of the performance tasks and a trough on the Comprehension subscale (Happé, 1994). Block Design requires the analysis of graphic designs with a strong gestalt into components corresponding to blocks and the use of these blocks to reconstruct the design. Successful analysis depends on the ability to resist the 'pull' of the overall design. Another task where weak central coherence is an advantage is the Children's Embedded Figures Test (Witkin, Oltman, Raskin, \& Karp, 1971), which requires identification of geometric forms in pictures of familiar objects. Weak central coherence enables concentration on the graphic components without distraction by the subject of the picture, for example detecting a triangle uninfluenced by recognizing that the drawing denotes a pram. Shah and Frith (1983) showed that a group of autistic children were more successful on this task than groups of normal children matched for mental age and of mildly mentally retarded children matched for mental and chronological age.

Pring, Hermelin, and Heavey (1995) have argued that weak central coherence may be advantageous for the development of savant skills. Being able to analyse a visual scene into constituent lines and shapes without meaning may clearly be helpful for a graphic artist. Pring et al. (1995) found autistic savant artists and artistically talented normal children were much faster on a block design task than controls matched for mental age and diagnosis. In discussing other savant skills, they suggested that weak central coherence might favour absolute pitch, which is common in musical savants (Miller, 1989) and might plausibly aid their reproduction of music. Heavey (1997) has also proposed that weak central coherence may help the development of skill in calendrical calculation. Weak central coherence may favour the learning of individual day-date combinations that, in her view, is the first step in developing date calculation skill. A study of our sample of 10 calendrical savants, which includes 8 
people with autism, failed to support this: none showed unusually high levels of performance on Block Design and variation in Block Design success did not markedly predict skill in calendrical calculation (O’Connor, Cowan, \& Samella, in press).

O'Connor and Hermelin (1991) suggested a tendency to preoccupation in people of limited cognitive ability may be necessary for high-level performance, but it could not be sufficient. Otherwise savant skills should be more common. Some extra ingredient is required. Exceptional memory has been suggested, both short and long term. Spitz and LaFontaine (1973) proposed savants were different from others with similar general intelligence because they had higher working memories. They found savants had higher digit spans than a control group matched for IQ. However, subsequent tests found inconsistencies and little evidence of general memory superiority (LaFontaine, cited in Hill, 1978). Also, Heavey (1997) found no difference in digit spans between a group of calendrical calculators and a group of controls matched for verbal IQ, chronological age, and diagnosis. While the groups did not differ in either short- or long-term recall of material unrelated to the calendar, her sample of calendrical calculators did exhibit a highly efficient, talent-specific memory ability. In comparison with controls, they recalled more calendar-related items.

Greater arithmetical ability than might be expected from their general intellectual ability might explain how people with limited intelligence could calculate dates. Several formulae for date-calculation exist that derive from the procedure described by Lewis Carroll (1887) and simplified by Spitz (1994). Hill (1978) published a procedure that is accurate only for the modern calendar, introduced by Pope Gregory and adopted by Spain, Italy, Portugal and France in 1582, and by Great Britain and the United States in 1752. Table 1 shows Hill's (1978) procedure. To carry this out involves mental arithmetic of the following sorts: division of 2 digit numbers by 4 into integers plus remainders, 
addition of several 1 and 2 digit numbers,

division of 1 and 2 digit numbers by 7 into integers plus remainders.

This method can be extended to other centuries by the addition of century numbers to the result of Step 5. For dates in the nineteenth century, the correction factor is 2; for the twentyfirst century, it is 6 . Thus 22nd June 1857 fell on a Monday and the 22nd June 2057 will fall on a Friday. The procedure does not demand much arithmetical ability. It simply requires competence in the integer arithmetic that most children learn to do in primary school. Indeed, puzzle books for children sometimes include it.

While some case reports indicate that even this arithmetic competence is beyond the calculators, these may have underestimated their abilities. Both Hill (1975) and Roberts (1945) claimed the calculators they studied could not do arithmetic involving numbers with more than one digit. Similarly, an early report of the mentally retarded identical twins, George and Charles, claimed that they too were unable to add, subtract, multiply or divide single digit numbers (Horwitz, Kestenbaum, Person, \& Jarvik, 1969). However, a subsequent report revised this view of George, the more talented twin who could answer dates from years between 100 and 40400 (Horwitz, Deming, \& Winter, 1969). Later, Sacks (1985) discovered that the twins would exchange six-figure prime numbers with each other, and once Sacks entered into their game progressed to ten-digit primes and beyond. To verify prime numbers would seem to require competence in division. The case of Kit provides another indication of how easy it is to underestimate calendrical calculators' arithmetical abilities (Ho, Tsang, \& Ho, 1991). While he performed poorly on the Arithmetic subtest of the WAIS, he was much better on the problems in the Stanford Diagnostic Mathematical Test. These included sums involving all four arithmetical operations. The authors suggested that differences in test items explained the discrepancy in results. The questions in the intelligence test were set in the context of 
social or real life situations. The Stanford test simply required manipulations of numbers. Dave provides another example of how arithmetical ability may be missed because it is constrained in some unusual way (Howe \& Smith, 1988). While he failed subtraction problems such as 'What is 1,981 minus 1,963 ?', he could, however, solve even harder problems when they were set in a calendrical context, such as 'If I was born in 1841, how old would I be in 2302?'.

Our investigation of the arithmetical abilities of 10 calendrical calculators illustrates the difficulties of generalising about arithmetical ability (Cowan, O’Connor, \& Samella, 1998). From their WAIS scores, none appeared exceptional, and only one had an arithmetic subscale score that was markedly superior to his general intelligence. However, four performed at or near ceiling level on the Graded Difficulty in Arithmetic test (Jackson \& Warrington, 1986) which assesses mental addition and subtraction using problems without stories. All 10 showed they could add and subtract two digit numbers but for some this competence only appeared in conversations with problems set in calendrical contexts. Only 5 showed any ability to do division.

In summary, calendrical savants are often obsessively preoccupied with calendars, dates, and routines. They show specific enhanced memory ability for calendrical material, and may be unusually adept at mental arithmetic. Whether these characteristics precede or follow the development of their ability is uncertain. The evidence is correlational. For example the common claim that calendrical calculators are good at remembering birthdays (Howe, 1989) may be a consequence of their date calculation skill: birthdays are what many may ask them to work out. Or it may reflect the fascination with dates that led them to study calendars and develop the skill. A problem for empirical study of what makes someone become a calendrical calculator is that existing studies overwhelmingly concern people who have already developed the skill, often several years in the past. If the talent were more common, then prospective 
studies might be feasible. We now turn to consider the methods for answering date questions.

Methods for answering date questions

If someone asks us what day a particular date in a different year and month will fall on, we would probably use a diary or a calendar. For more remote years in the past or future, we could consult a perpetual calendar, such as reference books include. For example the 1998 edition of Whitaker's Almanack publishes a set of 14 coded calendar templates, 7 for leap years and 7 for nonleap years, which differ according to the weekday for 1st January, and codes for each year from 1780 to 2040 . Finding the calendar for a particular year is simply a matter of matching the year code with the appropriate template. Some calendrical savants may be able to answer date questions because they have memorised the calendars corresponding to particular years or even the perpetual calendar scheme. Two calculators with ranges of about 30 years were thought to rely on memory for calendars (Hill, 1975; Roberts, 1945). Several with ranges between 200 and 600 years are supposed to have memorised perpetual calendars: they include Charles, the less talented twin studied by Horwitz et al. $(1965,1969)$, and the three calculators studied by Young and Nettelbeck (1994). Consistent with this claim, Young and Nettelbeck (1994) report that the calculators they studied readily identified which years had the same calendrical pattern and two spontaneously gave the perpetual calendar codes for the years.

Memory for calendars undoubtedly contributes to date calculation skill. It may be sufficient to explain the talent in those whose range is limited to the years whose calendars they have studied. However, it cannot explain the talent in blind savants who have never seen calendars (Rubin \& Monaghan, 1965). Nor can it account for the ability of some sighted calculators to answer date questions outside the range of calendars or perpetual calendars they have seen, e.g. George (Horwitz et al., 1965, 1969) and Kit (Ho et al., 1991). 
Another possible explanation is the use of a formula such as in Table 1. Repeated practice in using the formula might result in it being internalised. John Conway, a distinguished

Insert Table 1 about here

mathematician, has devised an algorithm for date calculation which he can use to answer date questions in less than two seconds (Alpert, 1999). Further practice may result in the internalised formula being carried out rapidly but below the level of conscious awareness. This apparently happened to a graduate student who learnt a formula for date calculation and practised using it (Rimland, 1978). While an internalised formula may underlie calendrical calculation in people of average or superior intelligence, some features of savant performance appear inconsistent with it. Apart from the doubts about their ability to comprehend and execute the formula in Table 1, several show patterns of latencies and errors that are hard to reconcile with the formula explanation. O'Connor \& Hermelin (1984) found that latency increased with remoteness from the present. Seven of their eight calendrical savants were slower for 1963 dates than 1983 dates. Considering the steps in the formula provides no reason to expect this. Significant error patterns for dates in other centuries have been reported by other investigators (Ho et al., 1991; Horwitz et al., 1965,1969; Howe \& Smith, 1988; Hurst \& Mulhall, 1988). Both Dave (Howe \& Smith, 1988) and TMK (Hurst \& Mulhall, 1988) were typically one day out for dates in the nineteenth century, consistent with their mistaken belief that 1900 was a leap year. TMK also made errors for dates in the twenty-first century consistent with his mistaken belief that 2000 would not be a leap year. Kit was also mistaken in his understanding of the calendar: he wrongly believed that all century years, years such as 1900 and 2000, were leap years (Ho et al., 1991). He knew that years separated by 28 
years in the same century are identical. However he had overgeneralised this, probably because of his ignorance about century years, to apply across centuries and had as a consequence formed the view that years 700 years apart were identical. He used his 700 year rule and the 28 year rule to calculate remote dates. He would add or subtract multiples of these numbers to find an equivalent to the target year in the current century. George knew that the Gregorian calendar repeats every 400 years (Horwitz et al., 1969) but he did not know when it was introduced or that the days had been dropped at the time of adoption. (When Spain adopted the Gregorian calendar, the days from $5^{\text {th }}$ to $14^{\text {th }}$ October 1582 were dropped. Great Britain omitted the days from $3^{\text {rd }}$ to $13^{\text {th }}$ September 1752 , on changing to the Gregorian calendar.) Like Kit, George used addition and subtraction to find proximal years equivalent to the target. A third basis for date calculation may be strategies using calendrical regularities (O’Connor \& Hermelin, 1984; Norris, 1990; Spitz, 1995). Some calendrical regularities concern many years, such as the 28-year and 400-year rules mentioned above. Others are narrower in scope. The one year, one day rule applies to adjacent nonleap years. It refers to the regularity that the same date falls on the following day in the following year, e.g. $1^{\text {st }}$ January 1998 a Thursday, $1^{\text {st }}$ January 1999 a Friday). Even more restricted in scope are correspondences between months within the same year, e.g. in any year $1^{\text {st }}$ March falls on the same day of the week as $1^{\text {st }}$ November. Lastly are regularities between days within a month: two days separated by an exact multiple of seven days fall on the same weekday. O'Connor and Hermelin (1984) reported that one savant spontaneously commented on consistencies between months and another on the 28 year rule. Hermelin and O'Connor (1986) found that most calculators were faster in calculating dates when primed by a date in a corresponding month. Several could apply their knowledge of the one year, one day rule to both an imaginary calendar with no leap years and a task with a sequence of colours. Knowledge of calendrical 
regularities may help a calculator learn calendars corresponding to particular years, by reducing the amount that needs to be learnt. Knowledge of these rules in conjunction with some known day-date correspondences might enable a savant to work out unknown day-date combinations.

In summary, three bases for calendrical calculation have been suggested: memory for calendars, internalised use of formulae, and a combination of memory and strategies based on calendrical regularities. Savants probably differ in how they calculate dates, so identifying the basis for one savant does not imply that is how others do it. The problem becomes how to identify a particular savant's method. Unfortunately if you ask savants how they answer date questions, they typically cannot tell you. Several features of performance make a particular method a more credible basis for performance. Someone dependent on memory for calendars might show unusually high knowledge of birthdays or other dates and a range restricted to the calendars they have seen. In contrast they should not compute while answering date questions. Nor should they make consistent errors on dates in other centuries. Someone using a formula should demonstrate ability in division but not variation in latency with remoteness, nor errors that are consistent with ignorance of which century years are leap years. Savants are likely to be using strategies based on calendrical regularities if they explicitly use these in working out dates, and take longer with more remote dates. The ability to use calendrical regularities to work out the answers to date questions on years outside their range is a positive indication that regularities influence their skill but it is not necessary. Both Norris (1990) and Spitz (1995) propose that savants may detect regularities at a level below consciousness and so lack the ability to articulate them.

Table 2 summarizes the results of our investigations of a sample of 10 calendrical calculators. Their IQs are from administering the Wechsler Adult Intelligence Scales and their 
Memory Quotients from the Wechsler Memory Scales. Range, consistent errors, explicit use

Insert Table 2 about here

of regularities and variation in latency with remoteness were derived from the sessions reported in O'Connor et al. (in press). We assessed their knowledge of birthdays and calendrical events by asking them to recall for each day in a specific month whether they knew anyone's birthday for that day or whether anything special had ever happened to them on that day. Where possible, we verified their recall with their carers. While no norms exist for this task, any number of events recalled greater than 4 seems unusually high, and any number greater than 10 particularly striking. Cowan et al. (1998) assessed their ability to divide numbers with both orally and visually presented sums. Their ability to apply regularities to dates outside their range was assessed by three types of item. Eight items assessed regularities within a year, e.g. ' $1{ }^{\text {st }}$ March 1758 was a Wednesday. What was the $1^{\text {st }}$ November 1758 ?' (Wednesday). We judged savants could apply these regularities if they correctly answered at least 7 items. Other items assessed knowledge of the relations between dates in adjacent years, e.g. ' $1^{\text {st }}$ May 1756 was a Saturday. What was the $1^{\text {st }}$ May 1757?' (Sunday). While four items concerned dates separated by 365 days like the example, two items concerned dates separated by 366 , e.g. ' $2^{\text {nd }}$ April 1759 was a Monday. What was the $2^{\text {nd }}$ April 1760?' (Wednesday). We considered savants could apply the one year, one day rule if they answered at least 5 items correctly. The 28 year rule was assessed with four items, e.g. ' $16^{\text {th }}$ December 1763 was a Friday. What was the $16^{\text {th }}$ December 1791?' (Friday). Savants who answered at least 3 items correctly showed they could apply this regularity.

Our sample varies in measured intelligence between severe intellectual disability and 
average intelligence. Their performance on the Wechsler Memory Scales shows similar variation. All apart from JB and PM have received a diagnosis of autism. Their ages range from 17 to 49 . While all are prodigious at answering date questions their range varies from about 60 years to over 800,000 .

Several characteristics of their performance make internalisation of a published formula an unlikely basis for the talents of any savant in the sample. All except BL reliably take longer to answer questions about more remote years. Several (BL, JG, PM, JB, and DK) show no ability to do the simple division required in the formula. In addition both DM and JG make consistent errors outside the current century and three savants (MW, HP, and GC) make explicit use of calendrical regularities such as the 28 year rule and 400 year rule in answering date questions.

Memory for calendars alone is also ruled out for those who make consistent errors (DM and JG) or explicit use of calendrical regularities (MW, HP, and GC). Presumably the talents of these savants derive from exploitation of calendrical regularities. DM and JG may like Kit (Ho et al., 1991) falsely generalise the 28 year rule to apply across century boundaries even when the century year is not a leap year. All five are fastest on dates in the last 30 years and generally slower outside this period. Possibly they may remember a period of years and use repeated addition and subtraction to bring a target year within range like Kit (Ho et al., 1991) and George (Horwitz et al., 1969).

Deciding whether the others rely on memory for calendars alone or in combination with a technique exploiting regularities of the calendar is not possible. All except BL were reliably slower on more remote dates but this may reflect either differences in practice or the use of regularities. Savants may receive more practice on more recent dates, as these are easier to check. They may also spend more time studying recent calendars as these are more widely 
available. While both PE and DK showed they knew and could apply calendrical regularities to dates outside their range, this knowledge may have followed their memorising of calendars. Although their parents report their range of dates is outside those of the calendars they have seen, both savants are over 30 years old and so their parents cannot be presumed to know everything about their experiences.

For the others, memory for calendars may seem more plausible but no firm conclusions can be reached. Despite PM's and JB's lack of ability to apply regularities, they may yet know them. Both Norris (1990) and Spitz (1995) have proposed that savants may extract and use calendrical regularities in date calculation without conscious awareness. Possibly the ability to apply such regularities on our tests requires conscious awareness. Both BL and PM show unusual memory for calendrical events, with BL being particularly remarkable. She recalled the dates of birth of many people and her mother was able to confirm her accuracy. This evidence is not conclusive as HP recalled about as many calendrical events and yet we are convinced he does not rely on recall of calendars alone. In contrast to BL, the events HP recalled were often historical, e.g. for $6^{\text {th }}$ January he recalled the birth of Richard II (1367), Joan of Arc (1412), and the wearing of tights by Keith Weller in a football match in 1979 (Leicester v Norwich, final score, 3-0). JB's performance provides no convincing evidence about her method.

In summary, we have reviewed explanations of why people become calendrical savants and how they answer date questions. Several questions remain unanswered although research makes certain possibilities unlikely. In common with the study of other exceptional individuals, we are handicapped by the typical pattern of investigating people with unusual gifts after these have already developed. This makes impossible any conclusive determination of what causes someone to become a savant. More progress can be made in determining what method the 
calculator uses but as our sample illustrates, some savants' methods are easier to determine than others. Knowing about their methods raises further questions. For example have those who use calendrical regularities discovered them by themselves or have they been taught? If they discovered them for themselves, how are they able to do this and how are they able to integrate this knowledge into a technique for answering date questions? Further insights may depend on the development of new techniques and tasks.

Understanding the talents of savants has important implications for general areas of psychology such as intelligence and learning. Indeed savant skills play a key role in the theories of intelligence proposed by Anderson (1992) and Gardner (1983). They have also prompted interest in unconscious learning (Norris, 1990; Spitz, 1995) and provoked insights into autistic cognition (Frith, 1989). Some psychologists believe that exceptional practice and effective technique are enough to explain the development of any exceptional talent (Ericsson \& Faivre, 1988). What makes people exceptional is the circumstances that lead them to develop relevant strategies and engage in sufficient practice (Howe, 1989). An earlier study challenged this view by finding that one ten-year-old calendrical savant (MW) was already faster than many adult savants (O’Connor \& Hermelin, 1992). However the issue is not settled, as we cannot rule out the possibility that MW had, despite his youth, practised more often or more effectively than the older savants. We still have much to learn about savant skills. 


\section{References}

Alpert, M. (1999, April). Not just fun and games. Scientific American, 280, 28-30.

Anderson, M. (1992). Intelligence and development: A cognitive theory. Oxford:

Blackwell.

Carroll, L. (1887). To find the day of the week for any given date. Nature, 35, 517.

Cowan, R., O'Connor, N., \& Samella, K. (1998). The arithmetical abilities of savant calendrical calculators. Manuscript submitted for publication.

Duffett-Smith, P. (1981). Practical astronomy with your calculator. (2nd ed.). Cambridge: Cambridge University Press.

Ericsson, K. A., \& Faivre, I. A. (1988). What's exceptional about exceptional abilities ? In L. K. Obler \& D. Fein (Eds.), The exceptional brain: Neuropsychology of talent and special abilities (pp. 436-473). New York: Guilford Press.

Frith, U. (1989). Autism: Explaining the enigma. Oxford: Blackwell.

Gardner, H. (1983). Frames of mind: The theory of multiple intelligences. London: Heinemann.

Gould, S. J. (1997). Questioning the millennium. London: Cape.

Happé, F. G. E. (1994). Wechsler IQ profile and theory of mind in autism: A research note. Journal of Child Psychology and Psychiatry, 35, 1461-1471.

Heavey, L. J. (1997). Memory in the calendar calculating savant. Unpublished PhD, Goldsmiths College, University of London.

Hermelin, B., \& O'Connor, N. (1986). Idiot savant calendrical calculators: Rules and regularities. Psychological Medicine, 16, 885-893.

Hill, A. L. (1975). An investigation of calendar calculating by an idiot savant. American Journal of Psychiatry, 132, 557-560. 
Hill, A. L. (1977). Idiot savants: Rate of incidence. Perceptual and Motor Skills, 44, 161-162.

Hill, A. L. (1978). Savants: Mentally retarded individuals with special skills. In N. R. Ellis (Ed.), International Review of Research in Mental Retardation (Vol. 9, pp. 277-298). London: Academic Press.

Ho, E. D. F., Tsang, A. K. T., \& Ho, D. Y. F. (1991). An investigation of the calendar calculation ability of a Chinese calendar savant. Journal of Autism and Developmental Disorders, 21, 315-327.

Horwitz, W. A., Deming, W. E., \& Winter, R. F. (1969). A further account of the idiots savants, experts with the calendar. American Journal of Psychiatry, 126, 412-415. Horwitz, W. A., Kestenbaum, C., Person, E., \& Jarvik, L. (1965). Identical twin "idiot savants"- calendar calculators. American Journal of Psychiatry, 121, 1075-1079.

Howe, M. J., \& Smith, J. (1988). Calendar calculating in "idiots savants": How do they do it? British Journal of Psychology, 79, 371-386.

Howe, M. J. A. (1989). Fragments of genius: The strange feats of idiots savants. London: Routledge.

Hurst, L. C., \& Mulhall, D. J. (1988). Another calendar savant. British Journal of Psychiatry, 152, 274-277.

Miller, L. K. (1989). Musical savants: Exceptional skill in the mentally retarded. Hilllsdale, NJ: Erlbaum.

Nettelbeck, T. (1999). Savant syndrome-rhyme without reason. In M. Anderson (Ed.), The development of intelligence (pp. 247-273). Hove, England: Psychology Press. Norris, D. (1990). How to build a connectionist idiot (savant). Cognition, 35, 277-291. O'Connor, N., Cowan, R., \& Samella, K. (in press). Calendrical calculation and 
intelligence. Intelligence.

O'Connor, N., \& Hermelin, B. (1984). Idiot savant calendrical calculators: Maths or memory? Psychological Medicine, 14, 801-806.

O'Connor, N., \& Hermelin, B. (1991). Talents and preoccupations in idiot-savants. Psychological Medicine, 21, 959-964.

O'Connor, N., \& Hermelin, B. (1992). Do young calendrical calculators improve with age? Journal of Child Psychology and Psychiatry, 33, 907-912.

Pring, L., Hermelin, B., \& Heavey, L. (1995). Savants, segments, art, and autism. Journal of Child Psychology and Psychiatry, 36, 1065-1076.

Rimland, B. (1978). Savant capabilities of autistic children and their cognitive implications. In G. Serban (Ed.), Cognitive deficits in the development of mental illness (pp. 43-65). New York: Brunner/Mazel.

Roberts, A. D. (1945). Case history of a so-called idiot savant. Journal of Genetic Psychology, 66, 259-265.

Rubin, E. J., \& Monaghan, S. (1965). Calendar calculation in a multiple-handicapped blind person. American Journal of Mental Deficiency, 70, 478-485.

Sacks, O. (1985). The man who mistook his wife for a hat. London: Pan.

Shah, A., \& Frith, U. (1983). An islet of ability in autistic children: A research note. Journal of Child Psychology and Psychiatry, 24, 613-620.

Spitz, H. H. (1994). Lewis Carroll's formula for calendar calculating. American Journal on Mental Retardation, 98, 601-606.

Spitz, H. H. (1995). Calendar calculating idiots savants and the smart unconscious. New Ideas in Psychology, 13, 167-182.

Spitz, H. H., \& LaFontaine, L. (1973). The digit span of idiots savants. American 
Journal of Mental Deficiency, 77, 757-759.

Tredgold, R. F., \& Soddy, K. (1956). Tredgold's text-book of mental deficiency. (9th ed.). London: Ballière, Tindall and Cox.

Treffert, D. A. (1989). Extraordinary people. London: Bantam.

Witkin, H. A., Oltman, P. K., Raskin, E., \& Karp, S. (1971). A manual for the embedded figures test. Palo Alto, CA: Consulting Psychologists Press.

Young, R. L., \& Nettelbeck, T. (1994). The "intelligence" of calendrical calculators. American Journal on Mental Retardation, 99, 186-200. 
Table 1 A Method For Calendrical Calculation (After Hill, 1978) For Dates In The Twentieth Century With The Example Of 23rd June 1957

Step 2 Divide the last two digits by four and ignore any remainder

Step 3 Take the code number of the month given below:
0 April, July
4 Feb., March, Nov.
1 Jan., Oct.
5 June
2 May
6 Sept., Dec.
3 Aug.

Step 4 Subtract one if the year is a leap year and the month is either January or February

Step 5 Take the date of the month 23

Step 6 Sum the results of steps 1 to 5 99

Step 7 Divide the total by seven 14 remainder 1

Step 8 Use the remainder to identify the day of the week (0 is 23rd June 1957 Saturday, 1 is Sunday, 2 is Monday, 3 is Tuesday, 4 is was a Sunday Wednesday, 5 is Thursday, 6 is Friday) 


\section{Calendrical Calculation}

23

Table 2 Savants' Wechsler IQs, Memory Quotients and Features of Their Date Calculation and Performance of Other Calendrical Tasks

\begin{tabular}{|c|c|c|c|c|c|c|c|c|c|c|c|}
\hline Savant & \multicolumn{2}{|c|}{ Wechsler } & \multicolumn{4}{|c|}{ Date calculation } & $\begin{array}{c}\text { Memory } \\
\text { Events }\end{array}$ & \multicolumn{2}{|l|}{ Arithmetic } & \multicolumn{2}{|c|}{ Regularities } \\
\hline $\mathrm{BL}$ & 50 & 50 & $1940-1997$ & & - & - & 31 & - & $?^{c}$ & $?$ & $?$ \\
\hline JG & 54 & 58 & $1772-2165$ & + & - & + & 14 & - & + & - & - \\
\hline PM & 58 & 57 & 1912 - 1997 & & - & + & 7 & - & - & - & + \\
\hline JB & 60 & 83 & $1940-1997$ & & - & + & 2 & - & - & - & - \\
\hline PE & 94 & 97 & 1912 - 2024 & - & - & + & 2 & + & + & + & + \\
\hline HP & 96 & 86 & $1772-12823$ & - & + & + & 30 & + & d & & \\
\hline GC & 97 & 86 & $1772-819206$ & - & + & + & 6 & + & + & + & + \\
\hline
\end{tabular}




\section{Calendrical Calculation}

${ }^{a}$ Makes errors consistent with ignorance of which century years are leap

${ }^{\mathrm{b}}$ Takes longer to answer more remote years

${ }^{c}$ We have yet to find a method of explaining the task to these savants

${ }^{\mathrm{d}}$ Not tested 